\title{
PEMILIHAN PEMASOK KAYU DENGAN MENGGUNAKAN METODE TECHNIQUE FOR ORDER PREFERENCE BY SIMILARITY TO IDEAL SOLUTION (TOPSIS)
}

\author{
Dian Eko Hari Purnomo ${ }^{1)}$, Tauhid Wisnu Broto ${ }^{2)}$ \\ ${ }^{1)}$ Politeknik ATK Yogyakarta, ${ }^{2}$ Politeknik Industri Furnitur dan Pengolahan Kayu \\ Email: dian.eko.hari.p@gmail.com
}

\begin{abstract}
ABSTRAK
PT. JQK merupakan suatu perusahaan manufaktur yang memproduksi furnitur.. PT. XYZ mempunyai dua jenis yaitu pemasok kontrak dan pemasok tidak kontrak. Saat ini, di perusahaan dalam melakukan pemilihan pemasok tidak kontrak menjadi pemasok kontrak terkadang mengalami kesulitan. Kesulitan tersebut terjadi karena belum adanya kriteria yang secara rinci dapat dipergunakan untuk pemilihan pemasok. Sehingga pada penelitian ini akan berusahaan menemukan kriteria-kriteria yang berpengaruh dalam pemilihan pemasok. Pengolahan data pada penelitian ini menggunakan metode Technique for Order Preference by Similarity to Ideal Solution (TOPSIS). Kriteria yang dapat mempengeruhi pemilihan pemasok adalah jumlah total, jumlah total kualitas satu, jumlah total kualitas dua, jumlah total katu rusak, jumlah pengiriman maksimal, jumlah maksimal kualitas satu, jumlah maksimal kualitas dua, jumlah maksimal rusak, jumlah pengiriman minimal, jumlah minimal kualitas satu, jumlah minimal kualitas dua, jumlah minimal rusak, kerutinan, harga kualitas satu dan harga kualitas dua. Berdasarkan hasil pengolahan data nantinya akan diberikan beberapa usulan kepada perusahaan pihak perusahaan terkait dengan hasil perhitungan dan nilai untuk masing-masing pemasok.
\end{abstract}

Kata kunci: Pemilihan Pemasok, TOPSIS, Pengambilan Keputusan.

\section{Pendahuluan}

PT. JQK merupakan suatu perusahaan manufaktur yang memproduksi furnitur. PT. JQK mempunyai beberapa bagian penting diantaranya adalah bagian produksi, bagian pergudangan, dan bagian pengiriman. Pada bagian pergudangan terdapat bagian yang mengurusi pemasok. Permintaan yang terus meningkat mengakibatkan sistem produksi perusahaan tidak mampu untuk memenuhi permintaan tersebut. Sehingga diperlukan adanya pemasok bahan baku berupa pemasok kayu untuk memenuhi permintaan konsumen. Diberbagai perusahaan manufaktur, persentase ongkos material bisa mencapai antara 40\%-70\% dari ongkos sebuah produk jadi [1]. Untuk itu perusahaan membeli bahan baku setengah jadi dari pemasok. Permasalahan mulai muncul ketika perusahaan akan memilih pemasok kontrak. Pihak perusahaan kesulitan dalam melakukan penilai terhadap pemasok yang akan dipilih menjadi pemasok kontrak. Hal ini, terjadi karena pihak perusahaan belum mempunyai kriteria-kriteria yang dapat digunakan untuk menilai pemasok. Salah satu faktor kesuksesan sebuah perusahaan adalah pemilihan pemasok [2].

Dapat dikatakan pemilihan pemasok adalah salah satu aktivitas penting pada bagian pengadaan untuk mencapai keunggulan bersaing [3]. Selain itu, pihak perusahaan belum menggunakan suatu metode tertentu untuk pemilihan pemasok kontrak. Pemilihan pemasok adalah permasalahan multi kriteria dimana setiap kriteria yang digunakan mempunyai kepentingan yang berbeda dan informasi mengenai hal tersebut tidak diketahui secara tepat. Dalam hal ini pemilihan pemasok yang berdasarkan penawaran harga yang rendah sudah tidak efisien lagi. Untuk mendapatkan kinerja rantai pasok yang maksimal harus menggabungkan kriteria lain yang relevan dengan tujuan perusahaan [4]. Tujuan dari penelitian ini adalah mengidentifikasi kriteria-kriteria yang dapat digunakan dalam pemilihan pemasok. Selain itu, melakukan penilaian terhadap pemasok kayu di PT. JQK

\section{Metode Penelitian}

Penelitian ini bertujuan untuk menentukan pemasok kayu mengacu kepada tahapan penelitian sebagai berikut:

1. Mempelajari sistem pembelian kayu dari pemasok. Wawancara dan observasi untuk mendapatkan variablevariable keputusan penting dalam pemilihan pemasok kayu.

2. Mengidentifikasi kriteria-kriteria yang dapat digunakan untuk penentuan pemasok kayu kontrak.

3. Melakukan pengumpulan data untuk penentuan bobot kriteria.

Copyright (C) 2019, Kaizen : Management Systems \& Industrial Engineering Journal ISSN 15222-96806 (print), ISSN $155222-95973$ (online) 


\section{KAIZEN : MANAGEMENT SYSTEMS \& INDUSTRIAL ENGINEERING JOURNAL VOL. 2 NO. 1 TEKNIK INDUSTRI UNIVERSITAS PGRI MADIUN}

4. Melakukan pengumpulan data untuk penentuan bobot masing-masing pemasok kayu ditinjau dari masingmasing kriteria.

5. Melakukan pengolahan data untuk penentuan bobot kriteria.

6. Melakukan pengolahan data untuk penentuan nilai pemasok kayu.

\section{Hasil dan Pembahasan}

Pada tahapan ini dijelaskan tentang hasil dan pembahasan dari tahapan penelitian yang dilakukan. Pengukuran hasil dan pembahsan dilakukan melalui beberapa tahapan yaitu kegiatan pembelian kayu, pemilihan pemasok kayu, penerapan model TOPSIS.

1. Kegiatan pembelian kayu

PT. JQK mempunyai cara tersendiri dalam proses pembelian kayu dari pemasok adalah sebagai berikut:

a) Pemasok kayu mengirimkan kayu olahan ke PT. JQK.

b) Bagian produksi PT. JQK khususnya pada stasiun kerja sortir A melakukan klasifikasi kayu menjadi tiga klasifikasi. Tiga klasifikasi tersebut adalah kayu kualitas satu, kayu kualitas dua dan kayu rusak. Proses pengklasifikasian ini sudah ada prosedurnya. Yang mana prosedur tersebut telah dibuat oleh bagian administrasi perusahaan berdasarkan penelitian secara langsung yang dilakukan oleh perusahaan.

c) Setelah pengklasifikasian dilakukan penghitungan untuk masing-masing jenis klasifikasi kayu.

d) Dilakukan pencatatan dan pemberian bukti pengiriman kepada pemasok.

e) Proses pembayaran dilakukan dengan cara menukarkan bukti pengiriman ke bagian administrasi.

2. Pemilihan kriteria pemasok

Pemilihan pemasok kayu berdasarkan kecocokan kriteria dari PT. JQK. Tabel 1. menunjukkan daftar kriteria yang dapat digunakan untuk pemilihan pemasok kayu, kriteria di bawah ini didasarkan pada ketentuan yang berlaku di PT. JQK saat ini. Data yang diperoleh 15 kriteria yang digunakan dalam memilih pemasok. Hasil dari pengukuran bersama dengan pihak PT. JQK dipilih 5 kriteria pemasok seperti pada Tabel 2. Pemasok yang dipilih maka dibuat hirarki dengan hubungan pemasok dengan kriteria yang ditentukan. Sususnan hirarki dapat dilihat pada Gambar 1.

Tabel 1. Daftar Kriteria Berdasarkan Ketentuan yang Berlaku

\begin{tabular}{|c|c|c|l|c|c|c|}
\hline No. & Kode & Kriteria & \multicolumn{1}{|c|}{ Penjelasan } & Jenis Kriteria & Satuan & Bobot \\
\hline 1 & $\mathrm{C} 1$ & $\begin{array}{c}\text { Jumlah } \\
\text { Total }\end{array}$ & $\begin{array}{l}\text { Jumlah total pengiriman } \\
\text { kayu }\end{array}$ & $\begin{array}{c}\text { Keuntungan } \\
(+)\end{array}$ & $\begin{array}{c}\text { Kilogram } \\
(\mathrm{Kg})\end{array}$ & 4 \\
\hline 2 & $\mathrm{C} 2$ & $\begin{array}{c}\text { Jumlah } \\
\text { Total } \\
\text { Kualitas 1 }\end{array}$ & $\begin{array}{l}\text { Semakin tinggi jumlah total } \\
\text { kayu yang memenuhi syarat } \\
\text { maka semakin baik }\end{array}$ & $\begin{array}{c}\text { Keuntungan } \\
(+)\end{array}$ & $\begin{array}{c}\text { Kilogram } \\
(\mathrm{Kg})\end{array}$ & 3 \\
\hline$\ldots$. & $\ldots$. & $\ldots$. & $\ldots$ & $\ldots$. & $\ldots$. \\
\hline 13 & $\mathrm{C} 13$ & Kerutinan & $\begin{array}{l}\text { Semakin sering pengiriman } \\
\text { kayu maka semakin baik }\end{array}$ & $\begin{array}{c}\text { Keuntungan } \\
(+)\end{array}$ & - & 5 \\
\hline 14 & $\mathrm{C} 14$ & $\begin{array}{c}\text { Harga } \\
\text { Kualitas 1 }\end{array}$ & $\begin{array}{l}\text { Semkin murah harga beli } \\
\text { kayu yang memenuhi syarat } \\
\text { maka semakin baik }\end{array}$ & Biaya (-) & $\begin{array}{c}\text { Rupiah } \\
\text { (Rp) }\end{array}$ & 4 \\
\hline C15 & $\begin{array}{l}\text { Harga } \\
\text { Kualitas 2 } \\
\text { kayu yang tidak memenuhi } \\
\text { syarat tetapi masih maka } \\
\text { semakin baik dapat } \\
\text { digunakan }\end{array}$ & Biaya (-) & $\begin{array}{c}\text { Rupiah } \\
\text { (Rp) }\end{array}$ & 3 \\
\hline
\end{tabular}

Tabel 2. Daftar Pemasok Kayu Yang Akan Dipilih

\begin{tabular}{|c|c|c|}
\hline No & Kode & Nama Pemasok \\
\hline 1 & A1 & Pemasok 1 \\
\hline 2 & A2 & Pemasok 2 \\
\hline 3 & A3 & Pemasok 3 \\
\hline 4 & A4 & Pemasok 4 \\
\hline 5 & A5 & Pemasok 5 \\
\hline
\end{tabular}

Copyright (C) 2019, Kaizen : Management Systems \& Industrial Engineering Journal ISSN 15222-96806 (print), ISSN 155222-95973 (online) 


\section{KAIZEN : MANAGEMENT SYSTEMS \& INDUSTRIAL ENGINEERING JOURNAL VOL. 2 NO. 1 TEKNIK INDUSTRI UNIVERSITAS PGRI MADIUN}

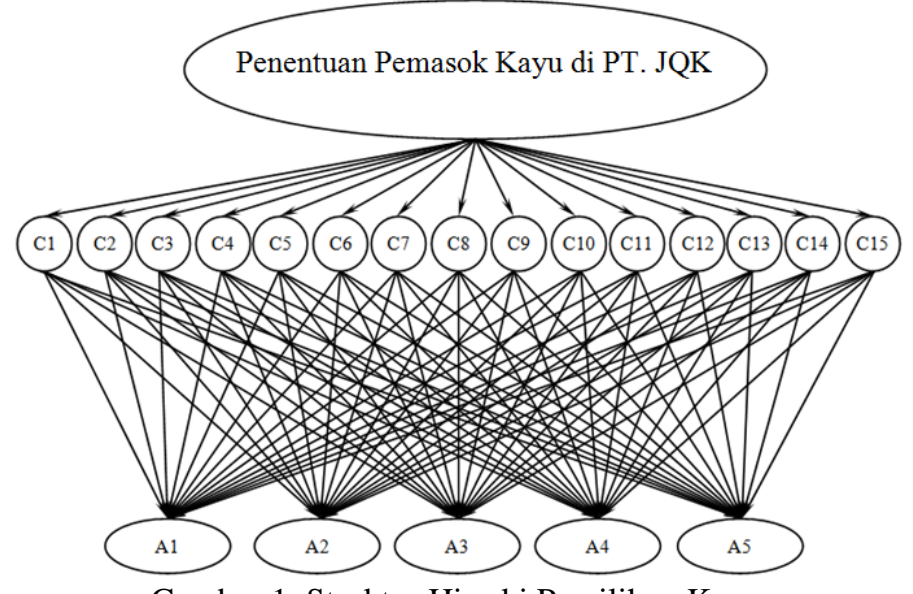

Gambar 1. Struktur Hirarki Pemilihan Kayu

3. Penerapan TOPSIS

Technique for Order Preference by Similarity to Ideal Solution (TOPSIS) didasarkan pada konsep di mana alternatif terpilih tidak hanya memiliki jarak terpendek dari solusi ideal positif, namun juga memiliki jarak terpanjang dari solusi ideal negative [5]. Secara umum, prosedur TOPSIS mengikuti langkah-langkah sebagai berikut

a) Membuat matriks keputusan yang ternomalisasi.

Tabel 3. menunjukkan hasil dari masing-masing kriteria yang sudah ternormalisasi. Perhitungan dari masing-masing kriteria sebagai berikut

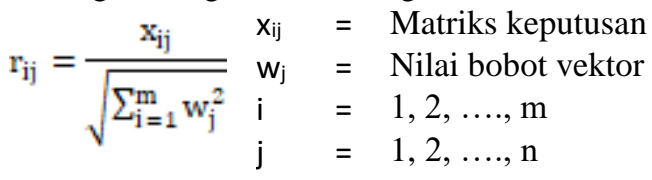

Tabel 3. Matriks Ternomalisasi untuk Metode Penyelesaian TOPSIS

\begin{tabular}{|c|c|c|c|c|c|}
\hline Alternatif & C1 & C2 & C3 & $\ldots$ & C15 \\
\hline Pemasok 1 & 0,452 & 0,452 & 0,431 & $\ldots$ & 0,577 \\
\hline Pemasok 2 & 0,448 & 0,527 & 0,323 & $\ldots$ & 0,385 \\
\hline Pemasok 3 & 0,448 & 0,452 & 0,431 & $\ldots$ & 0,385 \\
\hline Pemasok 4 & 0,514 & 0,414 & 0,647 & $\ldots$ & 0,192 \\
\hline Pemasok 5 & 0,360 & 0,377 & 0,323 & $\ldots$ & 0,577 \\
\hline
\end{tabular}

b) Membuat matriks keputusan yang ternomalisasi terbobot.

Tabel 4. menunjukkan hasil dari masing-masing kriteria yang sudah ternormalisasi terbobot. Perhitungan dari normalisasi dari kriteria adalah sebagai berikut

$y_{i j}=w_{i} \times r_{i j}$

$\mathrm{y}_{\mathrm{ij}}=$ Hasil matriks ternomalisasi

$\mathrm{i}=1,2, \ldots, \mathrm{m}$

$\mathrm{j} \quad=1,2, \ldots, \mathrm{n}$

Tabel 4. Matriks Ternomalisasi Terbobot

\begin{tabular}{|c|c|c|c|c|c|}
\hline Alternatif & C1 & C2 & C3 & $\ldots$ & C15 \\
\hline Bobot & $\mathbf{0 , 0 8 9}$ & $\mathbf{0 , 0 6 7}$ & $\mathbf{0 , 0 6 7}$ & $\ldots$ & $\mathbf{0 , 0 4 4}$ \\
\hline Pemasok 1 & 10300 & 6000 & 4000 & $\ldots$ & 1500 \\
\hline Pemasok 2 & 10200 & 7000 & 3000 & $\ldots$ & 1000 \\
\hline Pemasok 3 & 10200 & 6000 & 4000 & $\ldots$ & 1000 \\
\hline Pemasok 4 & 11700 & 5500 & 6000 & $\ldots$ & 500 \\
\hline Pemasok 5 & 8200 & 5000 & 3000 & $\ldots$ & 1500 \\
\hline
\end{tabular}

Copyright (C) 2019, Kaizen : Management Systems \& Industrial Engineering Journal ISSN 15222-96806 (print), ISSN 155222-95973 (online) 


\section{KAIZEN : MANAGEMENT SYSTEMS \& INDUSTRIAL ENGINEERING JOURNAL VOL. 2 NO. 1 TEKNIK INDUSTRI UNIVERSITAS PGRI MADIUN}

c) Menentukan matriks solusi ideal positif dan matriks solusi ideal negatif.

Tabel 5. dan Tabel 6 menunjukkan hasil dari solusi ideal positif dan negatif. Rumus dari perhitungan ideal posistif dan negatif adalah sebagai berikut

$$
\begin{aligned}
& A^{+}=\left(y_{1}^{+}, y_{2}^{+}, \ldots, y_{n}^{+}\right) \quad A^{-}=\left(y_{1}^{-}, y_{2}^{-}, \ldots, y_{n}^{-}\right) \\
& A \quad=\text { Nilai solusi ideal } \\
& y \quad=\text { Hasil normalisasi matriks }
\end{aligned}
$$

Tabel 5. Solusi Ideal Positif

\begin{tabular}{|c|c|c|c|c|c|}
\hline Alternatif & C1 & C2 & C3 & $\ldots$ & C15 \\
\hline Bobot & 0,040 & 0,030 & 0,029 & $\ldots$ & 0,038 \\
\hline Pemasok 1 & 0,040 & 0,035 & 0,022 & $\ldots$ & 0,026 \\
\hline Pemasok 2 & 0,040 & 0,030 & 0,029 & $\ldots$ & 0,026 \\
\hline Pemasok 3 & 0,046 & 0,028 & 0,043 & $\ldots$ & 0,013 \\
\hline Pemasok 4 & 0,032 & 0,025 & 0,022 & $\ldots$ & 0,038 \\
\hline Pemasok 5 & 0,040 & 0,030 & 0,029 & $\ldots$ & 0,038 \\
\hline $\left.\mathbf{( A}^{+}\right)$ & $\mathbf{0 . 0 4 6}$ & $\mathbf{0 . 0 3 5}$ & $\mathbf{0 . 0 2 2}$ & $\ldots$ & $\mathbf{0 , 0 1 3}$ \\
\hline
\end{tabular}

Tabel 6. Solusi Ideal Negatif

\begin{tabular}{|c|c|c|c|c|c|}
\hline Alternatif & C1 & C2 & C3 & $\ldots$ & C15 \\
\hline Pemasok 1 & 0,040 & 0,030 & 0,029 & $\ldots$ & 0,038 \\
\hline Pemasok 2 & 0,040 & 0,035 & 0,022 & $\ldots$ & 0,026 \\
\hline Pemasok 3 & 0,040 & 0,030 & 0,029 & $\ldots$ & 0,026 \\
\hline Pemasok 4 & 0,046 & 0,028 & 0,043 & $\ldots$ & 0,013 \\
\hline Pemasok 5 & 0,032 & 0,025 & 0,022 & $\ldots$ & 0,038 \\
\hline $\left.\mathbf{A}^{-}\right)$ & $\mathbf{0 , 0 3 2}$ & $\mathbf{0 , 0 2 5}$ & $\mathbf{0 , 0 4 3}$ & $\ldots$ & $\mathbf{0 , 0 3 8}$ \\
\hline
\end{tabular}

d) Menentukan jarak antara matrik ternormalisasi dengan matriks solusi ideal.

Tabel 7. menunjukkan hasil dari jarak antara nilai alternatif. Jarak dapat dihitung mengunakan rumus seperti dibawah ini

\begin{tabular}{|c|c|c|c|c|c|}
\hline Alternatif & D+ & D- & Alternatif & D+ & D- \\
\hline Pemasok 1 & 0,03626 & 0,05127 & Pemasok 4 & 0,02987 & 0,05782 \\
\hline Pemasok 2 & 0,03963 & 0,03858 & Pemasok 5 & 0,05217 & 0,03844 \\
\hline
\end{tabular}

$\mathrm{D}_{\mathrm{i}}^{+}=\sqrt{\sum_{\mathrm{j}=1}^{\mathrm{n}}\left(\mathrm{y}_{\mathrm{i}}^{+}-\mathrm{y}_{\mathrm{ij}}\right)^{2} \mathrm{i}_{s} \mathrm{j}}=1_{s} 2, \ldots \mathrm{m} \quad \mathrm{D}_{\mathrm{i}}^{-}=\sqrt{\sum_{\mathrm{j}=1}^{\mathrm{n}}\left(\mathrm{y}_{\mathrm{ij}}-\mathrm{y}_{\mathrm{i}}^{-}\right)^{2} \mathrm{i}_{s} \mathrm{j}}=1_{s}, \ldots \mathrm{m}$

Tabel 7. Jarak antara Nilai Alternatif

e) Mentukan nilai preferensi untuk setiap alternatif.

Tabel 8. menunjukkan hasil akhir nilai preferensi dari setiap alternatif. Perhitungan nilai preferensi dapat diperoleh melalui rumus

\begin{tabular}{|c|c|c|c|c|c|}
\hline Alternatif & D+ & D- & $\mathbf{V}$ & Persentase & Ranking \\
\hline Pemasok 1 & 0,03626 & 0,05127 & 0,58576 & $19,427 \%$ & 5 \\
\hline Pemasok 2 & 0,03963 & 0,03858 & 0,64868 & $21,285 \%$ & 1 \\
\hline Pemasok 3 & 0,03205 & 0,04993 & 0,59254 & $19,443 \%$ & 4 \\
\hline Pemasok 4 & 0,02987 & 0,05782 & 0,60954 & $20,001 \%$ & 2 \\
\hline Pemasok 5 & 0,05217 & 0,03844 & 0,60476 & $19,844 \%$ & 3 \\
\hline \multicolumn{3}{|c|}{ Total } & 2,77170 & $100 \%$ & \\
\hline
\end{tabular}
$V_{\mathrm{i}}=\frac{\mathrm{D}_{\mathrm{i}}^{-}}{\mathrm{D}_{\mathrm{i}}^{-}+\mathrm{D}_{\mathrm{i}}^{+}}$

Tabel 8. Hasil Akhir Metode Penyelesaian TOPSIS

Copyright (C) 2019, Kaizen : Management Systems \& Industrial Engineering Journal ISSN 15222-96806 (print), ISSN 155222-95973 (online) 


\section{Simpulan}

Berdasarkan kasus yang telah diteliti, diperoleh kesimpulan bahwa dari hasil peritungan di atas pemasok yang terpilih adalah Pemasok 2, karena mempunyai nilai persentase tertinggi berdasarkan metode TOPSIS. Kriteriakriteria yang dapat digunakan dalam pemilihan pemasok adalah jumlah total kayu, jumlah total kualitas 1, jumlah total kualitas 2, jumlah total rusak, jumlah pengiriman maksimal, jumlah maksimal kualitas 1, jumlah maksimal kualitas 2, jumlah maksimal rusak, jumlah pengiriman minimal, jumlah minimal kualitas 1, jumlah minimal kualitas 2, jumlah minimal rusak, kerutinan, harga kualitas 1, dan Harga Kualitas 2.

\section{Daftar Pustaka}

[1] I. N. Pujawan, Supply Chain Management. Surabaya: Guna Widya, 2005.

[2] C. Gencer and D. Gürpinar, "Analytic network process in supplier selection: A case study in an electronic firm," Appl. Math. Model., vol. 31, no. 11, pp. 2475-2486, 2007.

[3] A. Amid, S. H. Ghodsypour, and C. O'Brien, "A weighted maxmin model for fuzzy multi-objective supplier selection in a supply chain," Int. J. Prod. Econ., vol. 131, no. 1, pp. 139-145, 2011.

[4] W. L. Ng, "An Efficient and Simple Model for Multiple Criteria Supplier Selection Problem," Eur. J. Oper. Res., vol. 186, no. 3, pp. 1059-1067, 2008.

[5] S. H. Kusumadewi, A. S. Harjoko, and R. Wardoyo, Fuzzy Multi-Attribute Decision Making (FUZZY MADM). Yogyakarta: Graha Ilmu, 2006. 